\title{
Running Head: Activity-Based Learning Using Activity-Based Instructional Approaches in Electric Circuits
}

\author{
Rankhumise Mmushetji Petrus \\ Central University of Technology, Private Bag x20539, Bloemfontein, 9300, \\ Email: mprankhumise@cut.ac.za
}

\section{Doi:10.5901/mjss.2014.v5n15p400}

\begin{abstract}
This study examined the effectiveness of activity-based instructional approaches to teach electric circuits. The research population consisted of hundred (100) first year science education students enrolled at a South African university, both from South Africa's OBE-based curriculum (the NCS) and the Old school curriculum(OSC, the Nated 550). A pre-test/post-test comparison group design was followed. Data analysis was carried out by the use of the "t" test statistic, as well as the average normalised gain $\langle g\rangle$ scores. The findings showed highly statistically significant gains between the pre-test and post-test scores for both NCS and OSC groups on all the measures $(p<0,05)$. The average normalised gain was larger than 0,3 ,thus indicating the effectiveness of the intervention). There was no significant difference in the performance of the two groups.
\end{abstract}

Keywords: alternative/phrases: conceptions, change, electric circuits, activity-based instructional approaches, activity-theory

\section{Introduction}

Electricity constitutes an important part of the physics curriculum at both high school and higher education (HE) levels. Its significance in the syllabus is twofold: a study of electricity leads to the understanding of basic properties of matter and also to the understanding of the many practical applications of electricity in the modern world; and the understanding of electricity by an individual will, in all probability, help him/her to better understand an important part of the technological and natural world in which he/she lives (Caillot \& Xuan, 1993).

Activity theory (AT) ( Engeström \& Middleton, 1996) seeks to explain people's actions as they interact with their environment. This framework uses 'activity' as the basic unit for studying human practices and highlights the idea that the relationship between the subject and the object is not direct but rather mediated through the use of a tool. A tool can be something physical (e.g. apparatus) or intellectual (e.g., rules and roles displayed on handhelds). Physical tools are used to handle or manipulate objects while intellectual tools can be used to influence behaviour in one way or another

AT offers an appropriate platform from which to provide OBE-based instruction. One way it does this is that it clearly operationalizes the specific roles of each player /stakeholder in the implementation of the curriculum. Indeed, within the aegis of educational practice, AT has made significant contributions to the fields of computer supported collaborative learning (Bødker, 1997; Mwanza, 2001b; Nardi, 1996), human-computer interactions (Kuutti, 1996), and network communication and education (Engeström \& Middleton, 1996), among others.

Research has established that students benefit from activity-based programmes as such programmes are designed to encourage active learner involvement; and where students are organised into collaborative learning groups (Ramsden, 1994). The greater the student involvement, the better and more long-lasting their learning tends to be (Donnellan \& Roberts, 1985). The task of the educator as facilitator is to create learning conditions in which students actively engage in experiments, interpret and explain data and negotiate understandings of their findings with their peers (Taraban, et al., 2007).

Activity-based learning places particular emphasis on the use of everyday contexts as a starting point from which scientific concepts are developed and scientific ideas explored (Ramsden, 1994). In this way, learning starts from students' experiences and can be guided towards an understanding of concepts, methods and structures of physics as required (Lemmer \& Lemmer, 2005). A sequence of activities from contextual to conceptual to formal learning can be established. Concomitantly, an effective shift from students' alternative conceptions towards a conceptual understanding of the scientific concepts can then be formalized. If educators are aware of students' learning experiences and the ideas they hold about science, then they are better able to design instructional approaches that are in line with policy imperatives, and which are guided with current understanding about the way students' learn. What remain to be 
investigated is to what extent activity-based instructional approaches can alleviate the alternative conceptions. AT is geared towards practice. It embodies a qualitative approach that offers a different lens for analysing a learning process and its outcome, focusing on the activities people are engaged in.

An activity-based instructional approaches was used in the intervention because it is in line with the requirements of the National Curriculum Statements (Department of Education, $2003 \mathrm{a}$ and b), enahance learning and it also benefits disadvantaged learners. According (Taraban et al, 2007) it is constructivist in nature, since it provides opportunities for learners to express their pre-knowledge that can then be remedied by the facilitator

OBE is a strategy within the constructivist theoretical framework, which does not impose a prohibition on any instructional method. Furthermore, OBE provides the opportunity for implementing a number of different classroom activities and reflection on these, which could facilitate changing alternative conceptions. According to Gray (1997) one of the benefits of $\mathrm{OBE}$ is to foster critical thinking and to create motivated independent learners, This can best be achieved in a situation where a constructivist teaching approach with features of a constructivist programme, a constructivist teacher and a constructivist classroom are all in place.

According to Millar (1989), the process of constructing new ideas takes place within the learner's own head. This occurs when any successful learning takes place and is independent of the instruction method. A consequence of the constructivist approach is however that science should be taught with a view to elicit the active involvement of learners, which in turn leads to reconstruction of meaning. Millar further suggests that a change to the constructivist approach is more likely to be found in terms of improving the sequence and pacing of the science curriculum, and less in terms of changing instructional methods.

The South African education system is in a phase of fundamental reform, as opposed to incremental reform syllabus moving from a curriculum founded on a highly specified content-based, for each learning area in the curriculum, towards an outcomes-based education(OBE) curriculum in which the development of skills and attitudes has been given equal prominence to discipline content (Hobden, 2005:35).

Electricity applications encompass many aspects of our everyday lives. Beyond the school/ university curriculum or other module types, students need to understand electricity because it constitutes an aspect of energy; energy being a unifying concept in science. In essence, this is what makes it fertile ground for alternative conceptions, in which students develop views and imagery that are conceptually different from scientific ones (Nada, Iman \&Waisim, 2009). Indeed, since electricity is very common in everyday situations, it is natural that students should have many alternative conceptions about it (Caillot \& Xuan, 1993).

The research population consisted of hundred (100) first-year science students enrolled at a South African university both from the NCS and the OSC (Nated 550).. Both quantitative and qualitative data were collected. From the quantitative data, using McNemar and " $\mathrm{t}$ " test, the findings showed highly statistically significant gains between the preand post-test scores of both the NCS and OSC groups $(p<0,05)$, thus indicating the effectiveness of the intervention. The qualitative data showed that most of the alternative conceptions appeared to have been alleviated, No statistically significant difference was found between the normalised gains of NCS and OSC groups.

\section{Research Questions}

To what extent activity-based instructional approaches can alleviate the alternative conceptions?

What are the learning gains of NCS students compared to OSC students following any instructional intervention using activity-based instructional approaches, couched within OBE principles?

\section{Methods}

\subsection{Research Design}

The pre-experimental one-group pre-test-post-test research design was followed with a view to determining the effectiveness of the OBE activity-based intervention.

\subsection{Participants and Setting}

The study involved hundred (100) first-year university science education students enrolled at a South African University, both from the NCS and the OSC registered for the Electricity and Magnetism Module.

This study focused on OBE as a possible approach to fostering conceptual change in the study of electricity among 
first year physics students. Beyond being the official pedagogic approach for the country's education system at all levels, including HE, OBE held good promise for being a good and effective strategy - on its own merits and as espoused by its proponents. At the time of this study, the intake into the university comprised students who had completed high school from the old curriculum, as well as those who came from the new curriculum, which would have introduced them to science process skills and other applied competencies, as part of an OBE curriculum. These students would have brought with them a number of challenges to universities, particularly with regard to the instructional approaches in universities which still remain largely frontal, content-based and lecturer-centred - and taking place in large lecture halls not conducive to constructivist teaching approaches. Thus, one major focus area for this study was to determine whether changes in the curricula at the high school level, together with the accompanying changes in teaching approaches, effectively enhanced students' conceptual knowledge and understanding of electric circuits - thereby leading to a better state of preparedness for tertiary level studies.

\subsection{Data collection}

The Electric Circuits Concept Evaluation (ECCE) test, developed by Prof David Sokoloff to assess students' understanding of simple circuit concepts (Sokoloff, 1992), was used in this study as both a pre- and post-test. The test assesses students' understanding of current and potential difference in simple series and parallel circuits. The validity and reliability of the test were established by Engelhardt, (2004), who examined the feasibility of assessing students' conceptual understanding and potential use in evaluating the curricula using the ECCE test. The Kuder-Richardson formula 20(KR-20) was found to be less than 0.70 because of low discrimination and high difficulty indices.

The biographical information collected included the names of the previous schools the students had attended, their gender, and the year in which they completed Grade 12. The intervention strategies based on activity-based learning were developed. A variety of activities were chosen and sequenced so that students' conceptions could progressively be changed from their alternative conceptions into scientifically accepted ones. A post-test, the same as the pre-test, was administered at the end of the intervention in order to ascertain the effect of the intervention.

\subsection{Procedure}

First, a pre-test was administered to students for diagnostic purposes, i.e. to determine their prior knowledge concerning electric circuits. The identified prior knowledge was then used as a basis for developing the instructional materials in the field of electric circuits. These were based on succession of activities and discussions, and were aimed to enhance progression from contextual to conceptual, through to formal understanding of the concepts.

Secondly the intervention strategies based on activity-based learning were developed. A variety of activities were chosen and sequenced so that students' conceptions could progressively be changed from their alternative conceptions into scientifically accepted ones. These were based on succession of activities and discussions, and were aimed to enhance progression from contextual to conceptual, to formal understanding of the concepts. A post-test, the same as the pre-test, was administered at the end of the intervention in order to ascertain the effect of the intervention.

Finally during the post-activity discussion, the researcher introduced the concepts; electrical resistance, battery, current intensity, electric charges, electric field, electromotive force (emf) and the Law of Energy Conservation. With the acceptance of the analogy, students would have been able to understand and accept the interpretation of electric circuit experiments. After the students had understood the contextualized concepts and principles from the bicycle analogy, they were able to explain emf, the function of the battery and the law of energy conservation.

Given that this was an Action Research Project involving the researcher and his students, a number of pertinent ethical issues had to be considered. The researcher sought the support of the students by emphasising the importance of the research project and its benefits. A letter of consent was given to the students, and they all accepted to participate in the study.

\subsection{Data Analysis}

Data were analysed using average normalized gain scores in addressing the research questions of this study. According to Hake (2002a:3), the average normalized gain affords a consistent analysis of pre- and post-test data over a diverse learner population. Overall, average normalized gain is regarded as a much better indicator of the extent to which a treatment is effective - more so than is either the actual learning gain or the post-test results alone (Hake, 2002b: 2; Meltzer, 2002). If the treatment (e.g. an intervention) yields an average normalized gain larger than 0,3 for an instructional 
intervention, the intervention is considered to be in the "interactive-engagement zone" (Hake, 2002b). The, normalised learning gains were calculated in order to cross-validate the effectiveness of the intervention. The gains of students from the NCS programme were compared with those from the OSC curriculum. The t-test results were analysed to assess whether the means of the two groups are statistically different from each other

\section{Results}

The activity-based instructional approaches used in this study, which progressed from contextual to conceptual to formal understanding proved to be effective with an average normalised learning gain of 0.41 for NCS and0.42 OSC students. According to Hake (2002a), a treatment (e.g. an intervention) that yields a gain larger than $30 \%$ can be considered to be in the "interactive engagement zone".

\subsection{Results And Discussion Of Results}

\subsubsection{Performance of NCS and OSC groups on the pre-test}

In order to establish the equivalence of the two sub-groups (i.e. the NCS versus OSC) before the instructional intervention, the t-test statistic was applied to their performance on the pre-test. The result of this comparison is presented in Table 1.

Table 1: Comparison of pre-test scores for NCS and OSC students

\begin{tabular}{|c|c|c|c|c|c|c|}
\hline Group & Means & Sd & df & $t_{c}$ & $t_{0}$ & Results \\
\cline { 1 - 3 } NCS & 31.7 & 24.5 & \multirow{2}{*}{26} & 2.04 & 0.01 & $\mathrm{P}>0,05$ \\
\hline OSC & 33.1 & 23.8 & & & \\
\hline
\end{tabular}

The t-test did not yield a statistically significant difference between the pre-test scores of the two groups. The mean for the NCS pre-test was 31.7 ( $s d=24.5$ ) while the mean for the OSC pre-test was $33.1(s d=23.8), p>0.05$. This result is important in that any difference between the two groups that may be observed after the intervention may only be attributed to the effects of the intervention and not to any pre-existing conditions.

\subsubsection{The effect of the Instructional Intervention on the NCS students}

Table 2 presents the effect of the instructional intervention on redressing the identified learning difficulties with regard to the students from the NCS.

Table 2: Comparison of pre \& post test scores for NCS students

\begin{tabular}{lllllllll}
\hline Group Pretest Posttest & sd & df & $t_{c}$ & $t_{0}$ & Result & Inference \\
\hline Mean Mean & & & & & & \\
\hline OSC 31.7 & 60.6 & 24.5 & 13 & 1.76 & -4.3 & $\mathrm{p}<0.05$ & Significant \\
& 16.2 & & & & & \\
& & & & & & \\
\hline
\end{tabular}

The t-test yielded a statistically significant difference between the pre and post-test scores. The mean for the pre-test was $31.7(\mathrm{sd}=24.5)$ and the mean for the post-test was $60.6(\mathrm{sd}=16.2) ; p<0,05$. Therefore, there was a statistically significant difference between the pre-test and the post-test for the NCS group. This demonstrates that the intervention was effective, leading to the rejection of the null hypothesis, in favour of the alternative - namely, that an OBE activitybased instructional intervention led to statistically significant gain scores, in electric circuits, for students coming from the NCS.

Likewise, the comparison of pre- versus post-test scores of the OSC group also yielded a significantly different 
result (see Table 3).

Table 3: The effect of an OBE-based intervention on students from the OSC curriculum

\begin{tabular}{lllllllll}
\hline $\begin{array}{l}\text { Group Pretest Posttest } \\
\text { Mean Mean }\end{array}$ & sd & df & tc $_{c}$ & $t_{0}$ & Result & Inference \\
\hline OSC 33.1 & 62.6 & 23.8 & 13 & 1.76 & -4.3 & $\mathrm{p}<0.05$ & Significant
\end{tabular}

Here, too, the null hypothesis was rejected - suggesting that the intervention did have a significant effect on the performance of this sub-group of students.

\subsection{Normalised gain scores for the NCS group}

According to Hake (1998) and Meltzer (2002) $\langle\mathrm{g}\rangle$ is a much better indicator of the extent to which a treatment is effective, compared to either the gain or post-test scores alone. For example, if the treatment yields $\langle g\rangle\rangle 0.3$, then the course could be considered to fall inthe "interactive zone" Interactive engagement methods promote conceptual understanding through engagement of students in heads-on and hands-on activities which yield feedback through discussions with peers and /or teachers, all as judged by their literature description.Thus, as a way of cross-validiting the above statistical comparisons normalised gain scores were calculated in order to ascertain how much the NCS group benefitted from the intervention. The results are summarised in Table 5.

Table 4: Average normalised gain scores for NCS students $(n=50)$

\begin{tabular}{|c|c|c|c|c|}
\hline Pre-test Mean Scores & Post-test Mean Scores & Actual \% gain & Average normalised Gain score & $\%$ Gain \\
\hline 31.7 & 60.6 & 28.9 & 0.41 & 41 \\
\hline
\end{tabular}

The average score for the NCS group was $34 \%$ in the pre-test and this increased to $61.5 \%$ in the post-test, translating into $27 \%$ actual percentage gain, and an average normalised gain score of 0.4 . This fugure indicates the effectiveness of the intervention.

Actual percentage gain $=$ post-test - pre-test

$=60.6-31.7$

$=28.9 \%$

Maximum possible gain $=$ Total possible- actual gain

$=100-28.9$

$=71.1 \%$

Average normalised gain $=28.9 \% / 71.1 \%$

$=0.41$

\subsubsection{Average normalised gain scores}

To quantify the success of the intervention that set out to remedy students' learning difficulties related to electric circuits, and to compare the learning gains of the NCS versus OSCstudents, the average normalised gains were calculated using Hake's (1998) formula. This yielded the results reflected in Table 5. 
Table 5: Average normalised gain scores for NCS students $(n=50)$ and OSC students $(n=50)$

\begin{tabular}{|c|c|c|c|c|c|}
\hline Curriculum & Pre-test Mean Scores & Post-test Mean Scores & Actual \% gain & Average normalised Gain score & \%Gain \\
\hline NCS & 31.7 & 60.6 & 28.9 & 0.41 & 41 \\
\hline OSC & 33.1 & 62.6 & 29.5 & 0.42 & 42 \\
\hline
\end{tabular}

The average pre-test score for the OSC was $33.1 \%$ and 31.7 for the NCS and increased to $62.6 \%$ in the post-testfor theOSC and 60.6 for the NCSwhich translated to $29.5 \%$ actual gain for theOSC group and $28.9 \%$ for the NCS group. The average normalised gain score for the OSC was 0.42 and for NCS it was 0.41 , indicating the success of the intevention for both the groups.

\subsection{Comparison of post test results of NCS and OSC students}

The statistical comparison yielded a non -statistically significant difference between the post-test results of NCS and OSC students. The results are presented in Table 6.

Table 6:Comparison of post test results of NCS and OSC students

\begin{tabular}{|c|c|c|c|c|c|c|}
\hline Group & Means & $\mathrm{Sd}$ & $\mathrm{df}$ & $\mathrm{t}_{\mathrm{c}}$ & $\mathrm{t}_{0}$ & significance \\
\hline NCS & 60.6 & 16.2 & \multirow{2}{*}{26} & 2.04 & -0.45 & $\mathrm{P}>0,05$ \\
\hline OSC & 62.6 & 12.9 & & & \\
\hline
\end{tabular}

The test did not yield a statistically significant difference between the post-test scores of the two groups. The mean for the post-test for the NCS group was 60.6 as against 62.6 for the OSC students. Therefore, the hypothesis that students who studied under NCS would demonstrate significantly higher learning gains, as compared to those who matriculated from the OSC is rejected

\section{Discussion of Findings}

The results of this study indicated the effectiveness of the intervention in ameliorating students' alternative conceptions about electric circuits, regardless of which high school curriculum the participants came from. After students' alternative conceptions have been confronted through activity-based instructional approaches they were guided to construct scientifically acceptable knowledge. The knowledge was consistent with their experimental observations. However, contrary to the researcher's expectation that students who came from the OBE-based curriculum (the NCS group) would perform better than the group from OSC, the results of this study showed that the gains of the two groups were identical.

In discussion of the above findings set out above, starts with to what extent activity-based instructional approaches can alleviate the alternative conceptions. Lastly, a discussion and interpretation of the " $\mathrm{t}$ " test and gain scores is presented.

\subsection{Curriculum intervention based on Activity-based approaches with a view to redress the identified alternative conceptions}

\subsubsection{The effectiveness of the OBE-based intervention on NCS students}

The percentage of NCS students who answered the items right are higher compared to those who chose incorrect answers. This shows that there was an improvement in their results compared to the pre-test results, where incorrect responses scored higher percentage in almost all cases. It also emerged in the literature that alternative conceptions are difficult to overcome and explicit instructional interventions aimed at addressing these conceptions are necessary. This study also found this to be the case.

\subsubsection{The effectiveness of the OBE-based intervention on OSC students}

The percentage of OSC students who answered the items right are higher compared to those who chose incorrect answers. This shows that there is an improvement in their results compared to the pre-test where incorrect responses 
scored higher percentage in almost all cases. Making provision for different learning styles of the individual by applying a variety of instructional methods will help to promote effective learning. A tendency was identified by Novak (1998) that some students were most likely to favour rote learning approaches, and others were more constructivist in their approach, which means that they tend to favour meaningful learning strategies. Therefore both extremes need careful consideration in education (Coetzee, 2008).

\subsubsection{The effectiveness of the OBE-based intervention on NCS versus OSC students}

The percentage of the correct answers by from both groups is higher than $50 \%$ for most of the questions. The statistical comparison yielded a non-statistically significant difference between the post-test results for the two groups. There was an improvement in the post-test results for both groups, thus clearly indicating the success of the intervention.

The intervention used in this study was the OBE approach. The theoretical justifications from the literature showed that the OBE approach was powerful and had a number of strengths. One noteworthy, from the constructivist point of view, peer learning interactive engagement methods are strongly recommended for effective learning. By incorporating student-centered methods specifically by using students' questions, comments, responses on tests and, and generally adhering to the constructivist approach, it is possible to build models of students' knowledge construction which may help towards identifying of students' alternative conception (Coetzee, 2008). Only when alternative conceptions have been identified and directly addressed, will student learning become effective. Geer and Rudge (2002) state that students learn by making sense of phenomena as they experience them, as they evaluate their value and attempt to make sense of them within a socially acceptable context also in light of their prior knowledge.

\section{Interpretation and Discussion of the Results of the Gain Scores}

The average of the results from the pre-test to post-test increased dramatically for both NCS and OSC students. The average gain of both groups fall in the "interactive zone" (Hake,2002). The effectiveness of the strategies used in the intervention was, thus, comparable with contemporary interactive strategies The average normalised gains of both groups is slightly different and one of the reasons for this could be that many teachers are still teaching the new curriculum the same way as they were teaching in the old curriculum. The learning gain of the OSC students was 0.41 and for the NCS was 0.4 ,and consequently the null hypothesis was rejected which stated that students who studied under the NCS would demonstrate significantly higher learning gains after exposure to an Activity-based intervention, compared to those who matriculated from the old school curriculum.

The t-test yielded a statistically significant difference between the pre-test and post-test scores. The mean for the pre-test was $33.1(\mathrm{sd}=23.8)$ and the mean for the post-test was $62.6(\mathrm{sd}=12.9), p<0,05$. Therefore, there was a statistically significant difference between the pre-test and the post-test for the OSC group, which implied that the intervention had been effective. Consequently, the directional hypothesis, as stated, is accepted. This means that an Activity-based intervention will significantly alleviate the alternative conceptions held by first year science education students admitted from OSC curriculum about electric circuits

The t-test yielded a statistically significant difference between the pre and post-test scores. The mean for the pretest was $31.7(s d=24.5)$ and the mean for the post-test was $60.6(s d=16.2) ; p<0,05$. Therefore there was a statistically significant difference between the pre-test and the post-test for the NCS group. This demonstrated that the intervention was effective. Consequently, the directional hypothesis, as stated, is accepted. This means that an Activitybased intervention will significantly alleviate the alternative conceptions about electric circuits held by first year science education students, admitted from NCS high school curriculum. This is the result of Hypothesis

\section{Conclusion}

This high gain illustrates the success of the intervention in effecting conceptual change towards the correct scientific conceptions. The sequence of activities successfully enhanced the development of scientific conceptions. The results stress that it is necessary to implement the constructivist principle that students' initial understanding should be engaged and their conceptual understanding appropriately developed on the basis of their prior knowledge and understanding.

This study was conducted against the reported resilience of students' pre-concepts to extinction. The results of this investigation showed that an OBE-based activity-based instructional approach led to significant changes in alleviating students' pre-conceptions that is not consistent with espoused scientific thinking. To this end, this study has succeeded in achieving its objectives, thereby making a significant contribution to both theory and practice. 


\section{Implications}

This study involved a sample of 100 students. The high learning gain obtained illustrated the effectiveness of the intervention. It is therefore justified to infer that the activity-based instructional approaches followed in this study made a significant improvement in students' understanding of the science concepts that were studied.

The poor pre-test results showed that the students' alternative conceptions and learning difficulties related to electric circuits were not efficiently addressed in lower grades. This could be ascribed to a number of different factors, such as ineffective teaching, inappropriate textbooks, lack of facilities for practical work, and others.

On the basis of this and other studies (Redish, 2003 \& Trumper, 1990:353) it can be recommended that the following steps are followed when teaching and implementing interventions of this nature:

$\checkmark$ Start with what learners already know.

$\checkmark$ Treat learners' alternative conceptions with the urgency they require so that learners do not carry them to the subsequent years of study.

$\checkmark$ Use constructivist teaching-learning approaches (e.g. enquiry teaching-learning strategies) to promote conceptual change and understanding.

$\checkmark$ Create a list of terms with definitions in order to foster learners' understanding of requisite scientific terminology.

$\checkmark$ Relate the scientific knowledge that is being taught to its application in real life situations.

Teachers may also apply ideas from this study to research their own practices as well as to design learning and teaching experiences and materials for effective and meaningful learning and teaching (DoE, 2003:5). The value of researching one's practices as a teacher is the ability to be kept abreast with the dynamic nature of the teaching and learning environment.

An understanding of the alternative conceptions which students bring to the tertiary education sector will serve as a very important input into curriculation of university programmes. These alternative conceptions and teaching strategies, which may lead to the required conceptual changes, must be studied in science education modules by prospective science educators.

Educators and curriculum advisors need to be informed that it is crucial to understand both the prevalence and nature of alternative conceptions in order to effectively design and implement programmes that bring about the required conceptual changes to the teaching and learning practices of the science classroom.

\section{References}

Bødker, S. (1997). A human activity approach to user interfaces. Human-Computer Interaction 4:171- 195.

Calliot, M. \&Xuan, A.N. (1993). Adults' misconceptions in electricity: The proceeding of the third international seminar on misconceptions and educational strategies in Science and Mathematics (Ithaco, N, Y Misconception Trust).

Department Of Education.(2003). National Curriculum Statements for Grade10-12(General) physical science. Pretoria: Government Printer.

Donnellan, K.M \& Roberts, G.J. (1985). What research says? Science \& Children. January; 119-121.

Engeström, Y. (1987). Learning by expanding: An activity-theoretical approach to developmental research.Helsinki:Orienta-KonsultitOy.

Engeström, Y. \& Middleton, D. (1996).Cognition and communication at work. Boston, MA: Cambridge University Press.

Hake, R.R. (1998). Interactive - engagement vs. traditional methods: a six -thousand student survey of mechanics test data for introductory physics courses. American Journal of physics education research. 66(I):64-74

Hake, R.R. (2002a).Lesson from physics education reform. Conservation Ecology 52:8; online at <http:/l www.consecol.org/vol5/iss2/art28". Retrieved: 13/05/2011

Hobden, P (2005). What did you do in science today? Two case of Physical studies of 912 Physical Science classrooms. South African journal of science, 101,308-302.

Kabapinar, F. (2004).The design and evaluation of teaching -learning sequence addressing solubility concepts with Turkish secondary school students.International journal of science education, 26(5), 635-652.

Kuutti, K. (1991). Activity theory and its applications to information systems research and development.In H.-E Nissen, ed., Information Systems Research (pp. 529-549). Amsterdam: Elsevier Science Publishers.

Lemmer, M. \&Lemmer, T.N. (2005).Contextualization as a didactical approach to physics education. (In: Grayson,D.J (Eds). What physics should we teach? Proceedings of the international Physics Education Conference, Durban,5-8 July 2004,p212-218

Leont'ev, A. N. (1981). The problem of activity in psychology. In J. V. Wertsch (Ed.), Activity in soviet psychology (pp. 37-71). M. E. New York: Sharpe, Inc.

Meltzer, D.E. (2002b). Normalized gain: A key measure of student learning. Addendum to Meltzer 200a $;<$ http://www.physics.iastate.edu/per/articles/index.html>. Retrieved: 13/03/2011 
Mwanza, D. (2001b). Changing tools, changing attitudes: effects of introducing a CSCL system to promote learning at work. Proceedings of the Euro-CSCL 2001: 1st European Conference on Computer-Supported Collaborative Learning (pp. 470-477), Masstricht, The Netherlands.

Nada, C.A., Iman, O. \& Waisim, Z. (2009). Students' alternative conception about electricity and effects on inquiry based teaching strategies. International journal of science and mathematics education, 7:103-132.

Nardi, B. A. (1996). Context and consciousness: activity theory and human-computer interaction. Cambridge, MA: MIT Press.

Ramsden, J. (1994). Context and activity-based science in action. School science review.275(75): 7-14.

Sokoloff, D, (1992).Teaching Electric Circuit Concepts Using Microcomputer-Based Current/Voltage Probes. Proceedings of the NATO Advanced Research Workshop on Microcomputer-Based Laboratories. Amsterdam, November 9-13, 1992

Taraban, R., Box. C., Myers, R.M., Pollard, R. \& Bowen, C.W. (2007). Effects of active learning experiences on achievements, attitudes and behaviours in high school biology. Journal of research in science teaching, 44 (7):960-979.

Vygotsky, L. (1978). Mind in society: the development of higher psychological processes. Cambridge, MA: Harvard University Press. 